Article

\title{
Transcendentalism and Chinese Perceptions of Western Individualism and Spirituality
}

\author{
Sikong Zhao ${ }^{1, *}$ and Ionut Untea ${ }^{2}$ \\ 1 Institute of Philosophy, Shanghai Academy of Social Sciences, 1610 West Zhongshan Road, \\ Shanghai 200235, China \\ 2 School of Humanities, Department of Philosophy and Science, Wenke Building A, Jiulonghu Campus, \\ Southeast University, Nanjing 211189, China; untea_ionut@126.com or 108109055@seu.edu.cn \\ * Correspondence: zhaosikong@126.com or zhaosikong@sass.org.cn; Tel.: +86-021-64862266
}

Received: 3 July 2017; Accepted: 16 August 2017; Published: 22 August 2017

\begin{abstract}
The article presents essential aspects of the intellectual debates in China over the theoretical achievement of Transcendentalism to generate a conception of individualism that bears the mark of Confucian and Daoist influences. The peculiar profile of the Transcendentalist individual avoids western dimensions that have been perceived in China as overindividualistic. Therefore, the inquiry over Transcendentalism opens up the intellectual debates on how traditional Confucian and Daoist teachings may be used also in China to bring about a renewed conception of the self and the individual's life in social relationships that would be closer to a modern understanding of individualism. The Chinese problematization of the value of the individual in Chinese traditional culture sheds light on the non-western debates regarding cultural renewal.
\end{abstract}

Keywords: transcendentalism; individualism; humanism; Confucianism; Daoism; over-soul; vast-flowing vigor; comprehensive thinking; cultural renewal

\section{Introductory Remarks}

The connection operated by Transcendentalist thinkers between individualism and Chinese religions, has been acknowledged in western scholarship, although to a limited extent. One of the major causes of this limitation consists in the way the content of Asian religions has been appropriated by leading figures of Transcendentalism. As Arthur Versluis observes, Ralph Waldo Emerson read "countless" books emanating from the "Oriental" cultural space (Versluis 1993, p. 77). Given this "assimilation" of elements of Vedanta, Confucianism, and other "myths and ethical injunctions" from India, Persia, and China, the scholar's task to isolate the influence of one particular system of thought on the leading Transcendentalist thinker becomes an overcomplicated task: "so intertwined are these 'influences' on Emerson, and so much does he make them his own, that it is almost impossible to say where 'Emerson's thought' begins and his reinterpretation of Vedantic, Confucian, and other like currents ends" (Versluis 1993, p. 77). Versluis's interpretation is that what made possible this assimilation of the rich sources into one coherent whole was Emerson's "sense of contemporaneity with all ages", and his "attempted transcendence of temporal and cultural boundaries" (Versluis 1993, pp. 78-79). It is in this aspect that Versluis identifies a common perspective in Ralph Waldo Emerson and Henry David Thoreau in dealing with the rich thesaurus of the "Orient": "for both of them sought to return to origins, emphasizing inspiration and ignoring cultural context and ritual" (Versluis 1993, pp. 78-79). What distinguishes the two, in Versluis's opinion, is the way they make use of this heritage: on the one hand Emerson advances toward a path that Versluis calls "literary religion", that is a way "to return to origins intellectually", while Thoreau's approach was "to live", to experience this literary religion in practice: "Walden is an experiment in literary religion made actual" (Versluis 1993, pp. 78-79). 
It is significant that both Emerson's and Thoreau's perspectives are connected by Versluis's interpretation via a sense of atemporality and what may be called ideals of universal acculturation, since this opens up possibilities for an intercultural interpretation that is not led by a western-centered view. Nevertheless, an orientation toward a closer analysis of the Asian elements in Emerson's and Thoreau's Transcendentalism and a wider perspective, beyond the field of studies in western literature, seems to be discouraged by views that Emerson "came to Asian religious texts with a Platonist bent", or that both Emerson and Thoreau came rather with a literary interest toward these sources (Versluis 1993, p. 78). The present article explores the approaches emanating from Chinese scholarship emerging in early 1990s-at about the same period that Versluis's monograph was published in the west-up to contemporary times, in order to show Chinese scholars' interest for what they saw as an essential point where Transcendentalism had exerted an essential influence on American culture precisely under the impression left on its illustrious thinkers by traditional elements of Chinese culture. As we will argue, this essential point was the peculiar new face of the individualism that Emerson and Thoreau inserted into the American conception of the Enlightenment individual.

Versluis indeed acknowledges the influence of Confucianism on the forging of Emerson's and Thoreau's perspectives on the individual, and his relationships within society, or the influence of Daoism on Thoreau's conception on the relationship between the individual and nature. For instance, he remarks that Thoreau wrote in the first chapter of Walden that "the ancient philosophers, Chinese, Hindoo, Persian and Greek" lived "a more simple and meager life than the poor", and that no other class in history has been "poorer in outward riches", or "so rich in inward" (Thoreau 1989, p. 14). Versluis appreciates that the order chosen by Thoreau is "no accident", since Confucianism and the Laws of Manu had "the most to do with daily life" (Versluis 1993, p. 84). Moreover, Thoreau's project of living close to nature at Walden pond "closely parallels" the "love for and absorption into nature" as cultivated by Daoism (Versluis 1993, p. 93). At the same time, Versluis believes that "Confucianism reinforced Emerson's emphasis on the moral imperative for every individual", and that "the Confucian ideal of the ethical, solitary, learned, and decorous man" actually reinforced Emerson's "sense of himself in the face of all the retreats from society in which the other Transcendentalists engaged" (Versluis 1993, p. 70). Indeed, reacting to his fellow Transcendentalists' projects of getting closer to nature, Emerson puts forth "the Confucian ideal of the decorous and urbane scholar who refuses to leave society but seeks to perfect his relations with mankind" (Versluis 1993, p. 71).

This view on a "solitary" personality, but nevertheless engaged in an active relationship either with nature, or with other individuals in society, places not only Transcendentalist individualism as a particular positioning of human personality in the context of natural and social environments, but also brings together Confucian and Daoist perspectives in ways unexplored in Chinese tradition. This is the aspect that incites the most the Chinese scholarship on Transcendentalism. Beyond the question of the degree of influence of Chinese traditional culture and religion on the minds of the leading representatives of Transcendentalism, the peculiar position of Chinese scholars, emerging from the 1990s onwards, has been to advance toward a twofold perception of Transcendentalist individualism: on the one hand, to produce a theoretical perspective on the transformations of the American individualism under the influences of the Transcendentalism's conception of the self that owes to the Chinese traditional culture and religion; on the other hand, to explore the possibilities of a renewed sense of individualism and the self in the late twentieth-century and early twenty-first century Chinese society. As we will argue, this renewed individualism might be accomplished, according to the Chinese scholars Qian Mansu, Chen Changfang, Ni Feng, Xie Zhichao, Fang Hanwen and $\mathrm{Xu}$ Wen via a greater reception and awareness of the impact of Confucianism and Daoism on the western cultural model of individualism. This peculiar reception of Transcendentalism is not exclusively connected with literary studies, but also shows an opening toward cultural communication, a reinterpretation of Chinese political culture or religious traditions, and the ideal of a renewed understanding of a revolutionary self-cultivation. 
We chose to open this article with a first section dedicated to what appears, in our view, as three basic points of departure of the inquiries in Chinese scholarship about the theoretical connection between Transcendentalist individualism and Chinese traditional culture. The first point relates to Transcendentalist emphasis on the inner independence of the individual, that owes to the influence of Confucianism and Daoism; the second shows this independence as always connected to the social or natural environment of the individual; the third consists in the relative agreement of the Chinese scholars that Transcendentalist use of the Chinese view on the self remains significant for contemporary Chinese debates centered upon individualism. The second section deals with the way a central concept in Emerson's thought, the over-soul, has been compared with the traditional concept of "vast-flowing vigor". The aim of this inquiry consisted in showing how Chinese scholars reacted to a western concept forged under the influence of Chinese, and other Asian elements, together with western concepts. We found that the Chinese scholars' interest in drawing parallelisms between the over-soul and vast-flowing vigor has been fruitful, prompting reflections on western terms like "incarnation", "love", and "trinity", and deepening the Chinese scholars' interest in a version of Transcendentalist individualism that would avoid what they perceived as an overindividualistic American culture. In the third section we focused on Chinese scholars' critical views addressed to traditional elements of Confucianism and Daoism, and their inquiry on the theoretical possibilities of such traditional elements to make possible the emergence of a renewed Chinese perspective on the self and individual life that would be more compatible with a modern conception of the individual. From this point of view, the Transcendentalist model of the individual generated under the influence of Daoist and Confucian elements serves as an intellectual precedent for the Chinese scholars in search of a stricter individualist interpretation of the traditional views of the self. Qian Mansu's perspective on "comprehensive thinking" represents one of the more detailed arguments, aiming at transgressing the boundaries of a strictly moral interpretation of the self, and advancing toward a wider cultural acceptance of the value of the individual in the Chinese political and social spheres.

\section{Individual Life in Social Relationships}

In this preliminary part we illustrate how Chinese scholars acknowledge what is already known in western scholarship about the connection between Transcendentalism's peculiar conception of individualism and the influences of Chinese traditional culture. Nevertheless, if the point of departure is the common ground of the western and Chinese interpretations about the fruits of the importation of Chinese elements in the overall Transcendentalist conception of the individual, the Chinese scholars display a willingness to explore how their reading of the Transcendentalist individual feeds back into the contemporary intellectual representations of the Chinese traditional culture.

There are three preliminary points in which a view on Transcendentalist individualism emerges throughout Chinese scholarship. There are, of course, different intensities, given by different scholars, to each of these points, but their similarity of understanding of Transcendentalist individualism determined us to place the three points as foundational for the further development of the analysis. The first point is the Transcendentalist emphasis on a certain independence emanating from the self, but a kind of independence that, under the influence of Confucianism and Daoism, gives rise to a self-cultivation in all simplicity of life and connection to nature. Already in 1993, the year of the publication of Arthur Versluis's American Transcendentalism and Asian Religions, the Chinese scholar Ni Feng appreciates that, in virtue of the connection with the Chinese religion and culture, Thoreau placed a high emphasis on the destiny and the freedom of the "independent individual" (独立个体, dú lì gè tĭ) (Ni 1993, p. 110). A few years later, Qian Mansu connects Emerson's and Thoreau's conception on individualism with the Confucian and Daoist “idealized" (理想化, li xiăng huà) poverty. She states that, if Emerson manifested an admiration for this state of mind of poverty in Chinese culture, Thoreau actually went out to experience the Confucian idea by living in Walden (Qian 1996, pp. 74-75). The independence of the self gained a high visibility in the Transcendentalist reading of traditional 
Chinese elements, according to Xie Zhichao, due to Emerson's and Thoreau's interest in the individual's “intuition" (直觉, zhí jué) and "sensibility" (感悟, găn wù) (Xie 2007, p. 9).

The second point is the peculiar depiction of the individual's independence always in intimate connection with her or his milieu, be it nature or society. When speaking about the "independent individual" in Thoreau, Ni Feng considers that this independence remains conciliated, in Thoreau's thought, with the social and natural environment (Ni 1993, p. 110), while Qian sees this kind of connection between individual and milieu as the expression of Emerson's appeal to the Confucian Golden Rule: Never impose on others what you would not choose for yourself” (“己所不欲, 勿施于 人", jŭ suŏ bù yù, wù shī yú rén) (Qian 1996, p. 120). When talking about intuition and sensibility in Emerson and Thoreau, Xie puts them in direct relationship with the individual's "soul” (灵魂, líng hún), which is never isolated from reality. Because of this, "the influence of transcendentalism on American culture is very close to the influence of Confucianism on Chinese culture" [authors' translation] (Xie 2007, p. 9). According to Xie, it is the influence of the Confucian conception of "vast-flowing vigor" (浩然之气, hào rán zhī qì) on Emerson's idea of virtue that leads to the Transcendentalist conclusion that the individual's self-cultivation cannot be isolated from others (Xie 2007, p. 8).

Xie's interpretation also leads to the third point that we chose to briefly emphasize in this preliminary part, since he appreciates that Thoreau did adopt the conviction of the importance of self-cultivation, and maintained that "a man with good self-cultivation pursues truth, believes in justice and cares about others" [authors' translation] (Xie 2007, p. 8). This third point introduces the Chinese scholars' opinion that the study of western Transcendentalist individualism feeds back into the way traditional values are reinterpreted within the Chinese society at large, thanks to a fruitful Chinese reinterpretation of individualism within the framework of a cultural dialogue. Xie alludes to the Confucian idea that "personality is bound to be perfect" (人格必将完善, rén gé bì jiāng wán shàn), and to the ideal of the individual's state of "self-governance and self-consciousness" (自治自觉, zì zhì zì jué) (Xie 2007, p. 8). He sees in this aspect a close correspondence with Emerson's and Thoreau's conviction "that man is the inseparable part of nature, nature is man's teacher and friend" and their advocating of the "sublime human spirit and perfect morality in nature" [authors' translation] (Xie 2007, p. 9). This is always seen in Confucianism as an active orientation toward bettering the surrounding human and natural environment, an attitude which in modern interpretation might resonate well with ideas of progress and reform.

Well before Xie's article, Ni Feng had expressed a clearer commitment toward a conception of an individual that would reflect both western and Chinese aspirations: "[ $t]$ he real power of a society or a country is to solve the problems of this society or country by individuals" [authors' translation] (Ni 1993, p. 110). Nevertheless, Qian Mansu expresses the strongest intellectual stance of this individualistic ideal: "In the first half of 19th century, in America, Emerson launched a revolution in ideas-his new measure of evaluating everything is the alive soul of the individual person" [authors' translation] (Qian 1996, p. 1). The connection between the "alive soul” (活的灵魂, huó de líng hún) and the independent self-development of the individual is so strongly depicted by Qian, that she goes on to assert that "a person can make a contribution to society at least by making oneself into an 'individual', reach the standard of capital 'Man', develop people's potentiality of mind and morality, and even have a little Transcendental consciousness. This is the purpose of Emerson's Transcendentalism" [authors' translation] (Qian 1996, pp. 235-36). The last part of the sentence is striking, and reveals the aspect of a returning influence, on the intellectual understanding of Confucian Chinese contemporary values by Transcendentalism, a system of thought that had been originally constructed with traditional Confucian ideas. Moreover, she adds that Emerson, in spite of his admiration for the Confucian attitude to morality and self-cultivation, could not accept the Confucian view on hierarchy. That is why, Qian believes, while producing a new type of individualism within the American culture, Emerson also “refreshes the essence of Confucianism" (“复活了儒家思想中的精华”, fù huó le rú jiā sī xiăng zhōng de jīng huá) [authors' translation] (Qian 1996, p. ii). 
The three points briefly presented above make appear, in essence, many facets of the intricate connections between the Chinese traditional values and the Transcendentalist understanding of individualism. What follows is an exploration of a number of more detailed critical inquiries dedicated by certain Chinese scholars to specific aspects of the relations between Transcendentalist individualism and contemporary intellectual representations of the Chinese traditional culture.

\section{The Vast-Flowing Vigor and the Over-Soul}

One of the key elements that link Transcendentalism to the Chinese traditional cultural heritage remains Emerson's concept of "over-soul”. Although Emerson's over-soul contains indeed elements from multiple religious and philosophical traditions from both the East and the West, like Hindu, Chinese, Buddhist, Judeo-Christian, Greek Philosophy, and even from later philosophies like that of Emanuel Swedenborg or Friedrich Schelling (Dilworth 2010, p. 206), the aspect that drew the Chinese scholars' attention remained its connection to a way of expressing a kind of individualism that resonates well with contemporary representations of Chinese traditional culture. As Tiffany K. Wayne appreciates, the concept of over-soul indeed contributes to the forging of Emerson's "true individualism and originality of thought", as this individualism emerges, as Emerson indicates in his essay "The Over-Soul", through " the influx of the Divine mind into our mind" (Wayne 2006, p. 205; Emerson 2009, p. 203). In trying to represent the ecstatic experience of the "individual consciousness of that divine presence", Emerson uses terms like "submission" (Emerson 2009, p. 200) and "obedience" (Emerson 2009, p. 202), which receive nevertheless their full liberatory meaning at the light of phrases like "joyful perception", "enthusiasm", or "consciousness" (Emerson 2009, p. 203). They are meant to rehighlight a revelation of the over-soul that can only be an "individual's experience" (Emerson 2009, p. 203), and not one of a blind obedience in rituals dictated by official religious institutions. It is only after breaking with the god of tradition that God may "fire the heart with his presence" (Emerson 2009, p. 207). Emerson insists thus upon cultivating the individualistic experience of the divine, especially during "our lonely hours", when "the soul gives itself, alone, original and pure, to the Lonely, Original and Pure" (Emerson 2009, p. 208).

The over-soul that "both guides and is changed by humankind", being understood as a "human force that replaces a belief in God or the supernatural" (Wayne 2006, p. 205), has received particular attention in Chinese scholarship for several parallelisms that might be distinguished between some given facets of the over-soul and traditional Chinese concepts. For instance, Qian Mansu compares Laozi's "Dao" with Emerson's "over soul" and finds the following common aspects: "they are both all-inclusive, being-in-itself and being-for-itself, transcendental and perfect; they are both source and end of all things" (Qian 1996, p. 68). Fang Hanwen and Xu Wen also argue that there is a close parallelism between the concept of the over-soul and neo-Confucian concepts of $\mathrm{Li}$ (理) and Qi (气), as Li expresses soul's communication between man, nature and God, while Qi is the essence of Heaven and Earth and "the meaning of individual life" (Fang and Xu 2014, pp. 165-66). Nevertheless, the one who initiates, already in 1991, a closer analysis of the core concept of over-soul is Chen Changfang, who evaluates the influence of the Confucian concept of "vast-flowing vigor" (浩然之气, hào rán zhī qi) on Emerson's thinking.

Chen displays a critical reading of Emerson's over-soul by comparing the Transcendentalist concept with Mencius's vast-flowing vigor. He argues that the influence of the vast-flowing vigor on Emerson's thought modeled Emerson's view on an invisible spiritual power, but this influence was manifested upon a mind already bearing the mark of the western Christian heritage: "This metaphor of invisible spiritual power is exactly the certain incarnation of God and also the controlling power of different religions, e.g., 'love' in Christianity" (Chen 1991, p. 6). Chen emphasizes that "incarnation" and "love" have been placed in key points by Emerson, a gesture that actually transforms the original Confucian vision of the vast-flowing vigor. Chen's critical reading reveals both commonalities and differences between the Chinese and the American concepts. The common characteristics may be identified in: the perspective of a peculiar individualism, allowing any individual who develops the 
inner spirit to act outwardly in a moral manner; a vision of an omnipresent spirit that, in spite of its ubiquity remains "invisible", i.e., accessible only to those who take the pains and have the patience to orient themselves toward revelatory experiences in their natural or social milieu; a mysterious and invisible spirit which nevertheless exerts a "controlling" influence over individuals, but in such a way that it leaves enough space for the manifestation of the individual's inner freedom.

Nevertheless, Chen emphasizes rather the differences from the original Confucian understanding of the vast-flowing vigor: "Of course, this explanation is much different from the meaning in Mencius (... ). What Mencius emphasized is that inner personality, bounded by discipline, can be exteriorized into majestic moral power, and not that some omnipresent spirit can be internalized into moral meaning and image. This difference for Emerson is not clear and is ambiguous. Emerson cannot agree to put the mysterious source of human soul under any limit and bound" [authors' translation] (Chen 1991, p. 6). In spite of allowing a margin for the discussion on the similarities between Confucian vast-flowing vigor and Emerson's over-soul, which still presents vestigial features taken from Christianity, like "love" and "incarnation", Chen cautions about letting too much of the Christian heritage dominate the discourse on the over-soul: his point is that the individualism made possible by Transcendentalism under the influence of Confucianism works relatively well when it is about "exteriorizing" moral power, in turn Confucian heritage would not allow the reading of an internalization of the omnipresent spirit into a moral teaching or an image. Actually Emerson was able to operate this in virtue of his conception of the "incarnation" and of the "controlling power" of love. We may understand thus that Chen presents his reservations regarding the idea that the vast-flowing vigor itself could be perfected by human individual participation and still remain without limit or unbounded. In his perspective, which follows that of Mencius, the "inner personality" that represents the internal manifestation of the spirit can only express itself in exterior only if bounded by self-discipline.

It is in this point that Chen still remains attached to the necessity of guidance by sages, while Emerson's view refuses to acknowledge a privileged status of any sage. For instance, in "The Over-Soul", Emerson asserts: "It is of no use to preach to me from without. I can do that too easily myself. Jesus speaks always from within (...). The position men have given to Jesus, now for many centuries of history, is a position of authority." (Emerson 2009, p. 208). In spite of this difference, Chen's efforts toward an individualistic reading of the concentration of the vast-flowing vigor in a person's self remains closely connected to Emerson's vision, as he asserts: “The mandate of heaven is in me (...). The personality of things and persons is also my personality, but with different forms ( . . ); in this case, man can just be one of Heaven-Earth-Man" [authors' translation] (Chen 1991, p. 37). This remains an individualistic reading of Confucianism in the spirit of a Transcendentalist vision, since the mandate of heaven can become impersonated in any individual, the possibility of becoming a sage being thus open to anybody, even though the individual's soul is not superior to the areas of the vast-flowing vigor present in Heaven or Earth. This implication of Chen's interpretation is a departure from the Confucian insistence on the privileged status of the sage. In this point, in order to acquire a larger margin for his individualistic reading of the vast-flowing vigor, Chen links the vast-flowing vigor also to Thoreau's individualism, since "Thoreau cares about the self-elevation of the individual soul as Daoism does: purify mind and insight, cultivate oneself and get rid of desires, obey natural law, hope that all humans can reach the state of a harmonious and free relationship with Heaven and Earth and can be fused with all things into one" [authors' translation] (Chen 1991, p. 87).

The connection between the vast-flowing vigor and the individualistic interpretations of Emerson and Thoreau also attracts the attention of Xie Zhichao, who asserts that Emerson and Thoreau shared the idea of virtue with Confucianism and even that they borrowed the term of vast-flowing vigor "to explain the importance of virtue" [authors' translation] (Xie 2007, p. 8). Like Chen, Xie believes that Mencius's "vast-flowing vigor" was only partially understood by Thoreau and Emerson, but he appreciates the influence of the Confucian concept on Emerson and Thoreau's formulation of individualistic morality: Emerson and Thoreau "focus on the individual's intuition and sensibility as 
Confucianism advocated" [authors' translation] (Xie 2007, p. 9). In spite of the fact that "Emerson and Thoreau criticized alienation between man and nature produced by capitalist pell-mell development" (Xie 2007, p. 8), what limits the individualistic perspective initiated by Transcendentalism is its pragmatic aspect, because in Xie's view, Emerson thought that virtue was "more useful than power" (Xie 2007, p. 7).

Xie tends thus to suspect a possible pragmatic turn in the Transcendentalist individualism's take on Confucianism. He notes that Transcendentalism "borrows Confucian ideas about family, friends, communities to develop individualism", but the Transcendentalist version of individualism still illustrates strong ties to the "individual's independent freedom and individual will" [authors' translation] (Xie 2007, p. 7) that characterizes the broader western conception of individualism. Xie appreciates thus that the result of the confluence between western individualism and Confucian perspective on the self in the Transcendentalist thought points toward the adoption of the perspective of the centrality of virtues, but this emphasis on virtues may not have the same motivations as in Confucian thought. Xie's argument may be understood from the wider perspective of Confucianism on virtue, as in Confucianism virtues flow rather naturally from the inner self in immediate connection with family, friends, and community. That is why the way the vast-flowing vigor is internalized by the individual in Transcendentalism risks to be limited by the more general western conception of individualism, which may still involve preferences and judgments about what is useful for someone. Xie's suspicion reflects indeed Emerson's effort in countering the effect of the traditional philosophical problem in the west about the free choice. "What your heart thinks great, is great. The soul's emphasis is always right", Emerson notes in "Spiritual Laws" (Emerson 2009, p. 163). Nevertheless, Emerson's success in this point might only be limited, since the pragmatic aspect of choice is not completely eliminated in Emerson's argument, but rather subordinated to the power of the individual heart listening to the soul's guidance.

Qian Mansu is more optimistic than Xie Zhichao regarding the Transcendentalist individualist project based on the traditional Chinese values, as she believes that, in his conception of the over-soul, Emerson involved, besides elements from Confucianism, also moral elements of Daoism. The main reason is that, even if Emerson did not directly use Daoist texts, actually in virtue of the fact that "Confucianism focuses on the moral aspect of Dao" (Qian 1996, pp. 68-69), the dose of Daoism present in Emerson's moral thinking involved in his presentation of the over-soul was sufficient to effectively do away with the overindividualistic perspective of the west. That is why she openly expresses her confidence that "enthusiasm" and a "living soul" characterize an essential attitude in Emerson's individualistic thought (Qian 1996, p. 13). A key element that functions as a catalyst, in her opinion, for Emerson's dealing away with the western problem of the free choice is his rejection of organized Christianity: "He opposed traditional Christianity. His new standard for everything is the individual alive soul (活的灵魂, huó de líng hún) and the always-updating spirit of universe (宇宙之灵, yŭ zhòu zhī líng) which all the individuals' souls are connected with. This is spiritual religion, which has nothing to do with institutions, with ritual. Under the guidance of this new faith, Emerson split with the church, starting to advocate his ideas about over-soul and self-reliance, becoming the standard bearer of American Transcendentalism" [authors' translation] (Qian 1996, p. 2).

\section{Humanism and Individualism: Beyond the Temptation of Comprehensive Thinking}

The common aspects of the concept of the over-soul and the vast-flowing vigor have opened up a promising field of discussion regarding the Chinese perspectives on the self and the role of the individuality embedded in the intercultural, social and political milieus. As mentioned above, Chen Changfang expressed confidence that "the mandate of heaven" may be in every individual, provided that the individual works toward bettering the ones he enters in contact with, but warned about conceding too much confidence in the individual capacities to influence the vast-flowing vigor. In this point, by criticizing this Transcendentalist confidence, he also disagrees with the Transcendentalist model of contesting the authority of sages or the institutions promoting the sages' 
teachings. Nevertheless, Chen suggests that the ultimate authority comes from the vast-flowing vigor, which encompasses not only the humanity, but it is expressed at three levels: "man can just be one of Heaven-Earth-Man" (Chen 1991, p. 37).

Writing a few years later, Qian Mansu takes this issue further, and while she is arguing in the same direction as Chen, to preserve the idea of the equal influx of the vast-flowing vigor in all the three levels of existence, she places a specific emphasis on the individualist implications of the Confucian perspective. She succeeds in securing the traditional view of the equal influx of the spirit in the three levels of existence, by using a Christian terminology: "The Chinese trinity is Heaven-Earth-Man." (Qian 1996, p. 69). The use of the term "trinity" suggests this equality of influx and the fusion of Heaven-Earth-Man into one, and at the same time establishing a certain differentiation between them, while avoiding exclusivist individualism.

In order to harmonize this version of individualism with the perspective of the traditional Confucianism on the self, Qian talks about "Confucian humanism": "Confucian humanism has three aspects: worshiping the 'sacred', abstract, not concrete personified god; putting human interest above theocracy, placing man in the center of universe; focusing on the meaning of the human ethical relationships" [authors' translation] (Qian 1996, pp. 90-91). The fact that Confucianism is centered so much on "human affairs and things around man" can be explained, Qian asserts (Qian 1996, p. 97), because "in the Chinese Heaven-Earth-Man trinity, Man has actual superiority to Heaven" (Qian 1996, p. 96). We may understand that, in Qian's interpretation, this is just a superiority of the intensity of the way the vigor is made concrete within and by every individual, not a superiority in the influx of the vast-flowing vigor in every man. That is why only a few individuals can perfectly reflect the richness of the vast-flowing vigor: "sage is the man who embodies human ethical relationships perfectly" [authors' translation] (Qian 1996, p. 97).

This interpretation of Qian's view is also suggested by her peculiar statement, in the first pages of her book, recalling Protagoras's famous humanist dictum "man is the measure of all things", but this time reshaped as to resonate with both Transcendentalist and Confucian humanism: "Emerson's new measure of evaluating everything is the alive soul of the individual person (...) [H]e is sure that man has an independent value from God, and he himself can live a spiritual life independently from the church. (...) Religion becomes, eventually, purely spiritual, personal and ethical" [authors' translation] (Qian 1996, pp. 2-3). It is thus through the way the over-soul is individualized or given concrete intensity of life that the man advances toward the perfect virtuous status, and this personal advancement is not primarily related to following other sages' teachings.

Although referring directly to Emerson's critical attitude toward the church, she makes it clear that her argument is actually about any organized religion or system of thought. Is, in this respect, Confucianism an exception? Qian suggests that, given the influence of Confucianism on Emerson's conception of the over-soul, Confucianism has the humanistic resources that would allow a more individualized application and creative reinterpretation of the Confucian heritage. Nevertheless, throughout its history of thought, Confucianism allowed only a limited individualistic approach. For instance "for Confucius, there is only one truth, which is found by the ancient sage king" (Qian 1996, p. 186), while "Mencius is intolerant to different schools of thought of his time" (Qian 1996, p. 187). In other words, instead of a positive focus on the individual possibilities of advancing toward, and reaching the status of sage, Confucian teachers have preferred the negative approach, by rejecting relativism that could sow confusion in the individual souls: "Confucianism teaches people to follow ancient sages and not to deviate from ancestors' way. But Emerson insisted that the past must not stifle alive people, and creativity is the life of the soul, imitation is suicide for the soul" [authors' translation] (Qian 1996, p. 189). The challenge that contemporary interpretations of Confucianism are facing is thus to advance more decidedly on the path of individualism.

Comparing Qian Mansu's perspective to that of the other two intellectuals of the same era (Chen Changfang and Ni Feng), it may be observed that all three place an emphasis on the necessity for the Chinese theoretical discussions about self and individualism to extend beyond the sphere of 
interpersonal morality. Qian argues: "Confucianism has some potential for individualism, but the Confucian concept of self cannot become individualism. Because, first, Confucian self is a strictly moral concept, not a political or lawful one. It is mainly about a person's personality. But from the perspective of politics or society, individual is a part of group, individual's value lies in the social relationship" [authors' translation] (Qian 1996, p. 213). Qian hopes thus to initiate in her contemporary intellectual culture an endeavor to extend the inquiry and application of Confucian individualism to the political and social culture. The example of this renewal cannot exclusively come from traditional Chinese culture, because "there are some individualist elements in the Chinese traditional culture, but they have nothing to do with modern individualism" [authors' translation] (Qian 1996, p. 212). This explains the importance she finds in the reception of Transcendentalism by Chinese scholars working on Chinese humanism in the 1990s, since the Transcendentalist approach regarding the individual, an attitude that had been influenced by Confucian ideas, could constitute an important example of bringing about a Confucian-inspired modern individualism.

Taking Transcendentalist individualism as a source of inspiration for the exploration of the possibilities of traditional Chinese culture to enrich the content of individualism beyond its moral applications, Chen Changfang had stated that, in principle, according to the traditional ideas of the Chinese culture, the "mandate of heaven" could be exteriorized by any individual in virtuous relationships with his environment. Nevertheless he had found a smaller margin for a creative restatement of individualism in Confucianism, than in Daoism (Chen 1991, p. 37). Writing a few years later, Qian Mansu argues that, although Daoism does offer the traditional resources for a theoretical restatement of a Chinese version of modern individualism, the major setback that would appear for the theoretician consists in Daoism's retreat from society: "In Chinese philosophy, Daoism is the closest to individualism. Daoism advocates going back to nature ( . . ) focusing on inner freedom ( ... ), escaping society. ( . . . ) It is impossible for Daoism to set up a new social order to guarantee everybody's individual freedom" [authors' translation] (Qian 1996, p. 216).

Not only the moral, but also the social and political guarantee of individual freedom had also been the object of Ni Feng's theoretical preoccupations on widening the sphere of the application of the Chinese perspective on individualism. Ni Feng argues that Thoreau's social and political thought "centers around the person as an independent individual (独立个体, dú lì gè tî) and his social and natural environment", and concludes that "the real power of a society or a country is to solve the problems of this society or country by individuals" [authors' translation] (Ni 1993, p. 110). Although using the phrase "independent individual", Ni Feng signals that he is not talking about an exclusivist individualism, as he conceives an independent individual, but nevertheless engaged in his social and political environments. Ni Feng suggests that this peculiar position of an individual's independence voluntarily oriented toward solving the problems of his society and country resonates well with the traditional Chinese culture. Nevertheless, he argues that, if the society or the country benefit from the work of the individual toward practical and spiritual achievements, it follows naturally that this independence should be protected at both the societal and political level: "in Thoreau's political thinking, his focus has always been on protecting human rights and freedom, worrying about potential harms made by the government to the individual at the level of human rights and freedom" (Ni 1993, p. 116).

The discussion about the connection between Transcendentalist individualism and the extension of the sphere of traditional Chinese understanding of the self to include an individualism not only in morality, but also in society and the political community, is also raised by Xie Zhichao, who concedes that "Emerson and Thoreau found inspiration from Confucianism, especially from conceptions of individual and nature to make up for the shortcomings of Transcendentalism" [authors' translation]. Nevertheless, "Confucianism does not talk about individualism", but rather about the "individual living in social relationships" (Xie 2007, p. 7). Xie's suggested solution in conciliating the two apparent contradictory views, a version of individualism generated under the influence of the Chinese culture and a version of an individual life accepted by the mainstream traditional interpretation, consists in 
linking questions regarding individual value to the question of rights and liberties of the groups that they connect with: "According to Confucianism ( . . ) the value of the individual belongs to different groups" (Xie 2007, p. 7).

At the light of this idea, which Xie does not develop sufficiently, we may now go back to Qian Mansu's efforts of finding a solution for a higher visibility of the individual in the social and political spheres in order to observe that she had proposed a similar view. Taking as a point of departure the situation of a minority group in China, the Jewish community of Kaifeng, Qian believes that there is no perceived gap between their Jewish and Chinese identities, at least from the point of view of the Chinese political culture. This is mainly due, in her opinion, to the adoption, in the political sphere, of an attitude of inclusiveness, which remains the merit of Confucian traditional values: "The comprehensive thinking of Confucianism determines its inclusiveness, e.g., the Jews are assimilated into Chinese in Kaifeng, China, which is different from the Jewish isolated situation in other countries" [authors' translation] (Qian 1996, p. 78).

Her choice of talking about the Jewish community is meant to help her maintain that the Confucian traditional values inspired a Chinese culture of inclusiveness toward Jews for many centuries, in contrast with the negative perception of Jewish communities in the political and social cultures of the European countries. Nevertheless, although she finds positive the aspect of inclusiveness, she warns that this kind of attitude, if reinforced unilaterally by the state, or the majority groups, may lead to what she calls "nihilism", i.e., the erasure of all that makes the specific of a particular community: "The tendency of comprehensive thinking is to find commons instead of discussing about differences (...). If taken to the extreme, this way of thinking may lead to nihilism" (Qian 1996, p. 78).

Qian does not hesitate to express her opinion that even "Zhuangzi's On Leveling All Things (《齐物论》) has this tendency to nihilism" [authors' translation] (Qian 1996, p. 78). Erasing the individual identities for the sake of inclusiveness may generate "nihilism", a word with strong anti-social connotations. Qian indicates thus the danger of a clash of identities and the social turmoil that would be generated by misrepresented traditional ideals of inclusiveness. The temptation of comprehensive thinking, Qian suggests, characterizes all modern political cultures, as even "Emerson's thinking tends to comprehension too, but his background of the western tradition balances it" [authors' translation] (Qian 1996, p. 78). In other words, it is the background of the value of the individual and his freedom that discourages the all-too inclusive attitudes of majorities in western political communities, even if, as we have seen, this background had given Emerson a hard time conciliating the western philosophical problem of the free choice with his own conception of spiritual laws (Emerson 2009, p. 163).

If comprehensive thinking can be kept away from radical applications, Qian expresses hopes that it may become a medium of reciprocal exchange and assimilation of wisdom, even if this means assimilating new wisdom, that doesn't characterize a traditional culture throughout its history: according to Emerson, comprehension means to "assimilate the true and the good in anybody's thinking" (Qian 1996, p. 78). This means that this attitude of acculturation may prove itself fruitful for both majority and minority groups, and opens up the political culture of the majority toward the assimilation of new insights, allowing fresh reevaluations of the elements provided by the majority group's historical and cultural heritage. In Qian's case, the Transcendentalist model appears as an important cultural opportunity to reorient the resources of the traditional Chinese culture toward a revolutionary take on the internal possibilities of the Confucian self engaged in his surrounding milieu.

\section{Conclusions}

The Chinese cultural influence on Transcendentalism has received only a limited attention in western scholarship, given the western perception of the "Oriental" thesaurus explored by Emerson and Thoreau as a conglomerate of elements melted and reshaped into the two thinkers' ideal of a "literary religion". The theoretical reason behind the exploration of the Chinese influences consists 
in showing that, in spite of the perceived Transcendentalist melting pot, traditional Chinese elements have not been distorted, but rather the intellectual and spiritual experiment performed by the Transcendentalists have given these elements a special elasticity, that has been positively received by Chinese scholars. The inquiry over the role of traditional cultural elements of Confucianism and Daoism in shaping Emerson's or Thoreau's conception of the individual is not strictly an issue that concerns only Chinese scholars, as it might be interpreted, but rather concerns the larger framework of cultural exchange.

It seems indeed striking to learn from a Chinese scholar like Qian Mansu that Emerson, born and brought about in a cultural space external to the Chinese culture, has oriented himself toward an attitude that "refreshes the essence of Confucianism". As we have seen, this kind of assertion is indeed backed by an argument about the importance of the openness toward "comprehensive thinking" and "inclusiveness". As we have seen, Chinese scholars responded to the Transcendentalist attitude of using traditional Chinese terms with the willingness to explore the possibilities of western terms like "incarnation" and "trinity" in order to generate a comparative approach accessible to the modern day intellectual living in China and being acquainted with core western values. Another particularly striking assertion, coming from Chen Changfang, "the mandate of heaven is in me", is meant to suggest to the Chinese intellectual audience that the vast-flowing vigor may become activated not only in idealized historical sages or institutions, but also within the personal self of any individual. This is one of the main aims of the debates regarding the connection between Emerson's over-soul and the vast-flowing vigor. Although we find relative agreement in Chen Changfang, Ni Feng, Qian Mansu and Xie Zhichao that the Chinese version of individualism should avoid an exclusivist individualism that is most characteristic to western culture, their separate efforts converge in the way they are problematizing the limits imposed on the self by the Chinese traditional culture. The aim of this problematization has been the widening of the attention given to the value of the self and individual life, not only in moral matters, but also in the area of the political culture and social mentalities. Taking transcendentalism as a source of inspiration, Chen, Ni, Qian and Xie seem to agree that this renewal in cultural perception remains possible if the traditional resources of Confucianism and Daoism are involved in a creative way in cultural renewal and dialogue.

One of the possible solutions regarding the place and value of the individual in Chinese contemporary political and social culture and mentalities has been suggested by Xie Zhichao, and in a more detailed manner by Qian Mansu. She argues that a model of "inclusiveness" should be pursued, as it has been fruitful in the past and in addition has been inspired by the Chinese traditional culture. At the same time she insists upon refreshing the essence of this model by introducing new perceptions of the Chinese traditional culture that have generated social change in other cultural spaces. She intends thus to raise awareness about the positive impact of the model of Transcendentalist individualism upon humanism as understood in China.

Qian's term "assimilation", and her example of the Jewish community of Kaifeng, may raise questions about Qian's model of cultural exchange. Nonetheless, the emphasis she places on the necessity of avoiding "nihilism" reveals her view on refreshing the idea of assimilation itself in the Chinese intellectual understanding. That is why, following the Transcendentalist model, she talks about assimilating wisdom, a dynamic attitude which, in her opinion, should be reciprocal: the Jewish community was "assimilated" in the sense that the Chinese larger culture assimilated "the true and the good" in their thinking, and also that the "the true and the good" of the Chinese traditional culture has been assimilated by the Jewish community in Kaifeng during the centuries that they lived in China and enjoyed a wider freedom, than in the European countries, to identify common grounds, to link their Jewish and wider identities together.

This is a rather optimistic reading of this phenomenon of acculturation as a reciprocal assimilation of wisdom, but Qian hopes to present the model of Transcendentalist individualism as an opportunity to refresh the debate on cultural exchange, and provide a reinforced theoretical model for promoting a stronger conception of individualism embedded in the Chinese framework of thought. Qian Mansu's 
model of "comprehensive thinking", together with elements of the theoretical interpretations of Chen Changfang, Ni Feng, Xie Zhichao, Fang Hanwen and Xu Wen on the use of Confucianism and Daoism by Emerson and Thoreau, show how Transcendentalist individualism has brought, in the late twentieth century and contemporary Chinese intellectual space, a new opportunity for inquiry upon the resources of the Chinese traditional culture to reinvigorate the theoretical debates about humanism and the value of the individual.

Author Contributions: S.Z. had the original idea, and designed the work plan after consulting with I.U. S.Z. translated the Chinese texts into English and received assistance from I.U. regarding the philosophical implications of the translated texts for a western audience. Both S.Z. and I.U. worked separately and jointly on several drafts before assembling the final draft. I.U. gave the English formulation and style of the text, and S.Z. made the final revision.

Conflicts of Interest: The authors declare no conflict of interest.

\section{References}

Chen, Changfang. 1991. Thoreau and China (梭罗与中国). Taibei: San Min Book.

Dilworth, David A. 2010. The Over-Soul. In Critical Companion to Ralph Waldo Emerson; a Literary Reference to His Life and Work. Edited by Tiffany K. Wayne. New York: Facts on File, pp. 206-9.

Emerson, Ralph Waldo. 2009. Essays and Lectures. Overland Park: Digireads.

Fang, Hanwen, and Wen Xu. 2014. Interpretation and Reconstruction of Emerson's Transcendentalism on Chinese Confucian Humanity Thinking (美国爱默生超验主义对中国儒学人文思想的阐释与再建). Social Sciences in Guangdong 2: 162-69.

Ni, Feng. 1993. The Political Thought of Henry D. Thoreau (梭罗政治思想述评). American Studies Quarterly 4: $107-28$.

Qian, Mansu. 1996. Emerson and China: Reflecting on Individualism (爱默生和中国: 对个人主义的反思). Beijing: SDX Joint Publishing Company.

Thoreau, Henry D. 1989. Walden. Princeton: Princeton University Press.

Versluis, Arthur. 1993. American Transcendentalism and Asian Religions. New York and Oxford: Oxford University Press.

Wayne, Tiffany K. 2006. Encyclopedia of Transcendentalism; the Essential Guide to the Lives and Works of Transcendentalist Writers. New York: Facts on File.

Xie, Zhichao. 2007. The Meeting of American Transcendentalism and Chinese Four Books (美国超验主义与中国 《四书》的碰撞). Social Sciences in Hunan 3: 6-9.

(C) 2017 by the authors. Licensee MDPI, Basel, Switzerland. This article is an open access article distributed under the terms and conditions of the Creative Commons Attribution (CC BY) license (http://creativecommons.org/licenses/by/4.0/). 